\title{
KNOWLEDGE SHARING PENGGUNAAN APLIKASI PENGARSIPAN ELEKTRONIK DENGAN IMAGE WARE SCAN MANAGER DAN APLIKASI WORDPRESS DI MITRA SMKN 1 CISARUA
}

\author{
${ }^{1}$ Mamun Sutisna, ${ }^{2}$ Mukaram, ${ }^{3}$ Ermina Tiorida, ${ }^{4}$ Mohammad Rizal Gaffar, ${ }^{5}$ Tangguh Dwi \\ Pramono, ${ }^{6}$ Yayan Firmansyah \\ 1,2,3,4,5,6, Politeknik Negeri Bandung, Bandung, Indonesia \\ email: yayan.firmansyah@polban.ac.id
}

(Diterima: 17 September 2021; Direvisi: 27 September 2021; Dipublikasikan: November 2021)

\begin{abstract}
Abstrak
Kurikulum Baru yang merevisi Kurikulum SMK 2018, Revisi menitik beratkan pada penggunaan teknologi informasi dan telekomunikasi. Pada kurikulum tersebut terjadi beberapa pembaharuan seperti munculnya nama Otomatisasi dan Tata Kelola Perkantoran dan juga munculnya mata pelajaran yang berbau digital dan teknologi. Salah satu mata pelajaran yang disoroti adalah pengarsipan elektronik untuk menjawab tantangan tersebut. Tujuan pengabdian ini untuk meningkatkan kompetensi guru-guru dan staf SMKN Cisarua dalam bidang sistem kerasipan elektronik dengan program IWSM dan pengenalan aplikasi wordpress. Metode pengabdian ini hybrid. Hasil evaluasi rata-rata nilai post test dibandingkan pre-test mengalami kenaikan sebesar $18 \%$ ini menunjukan hasil yang positif. Dengan tingkat kehadiran peserta pelatihan selama 5 hari sebesar $82,4 \%$. Ini menandakan antusiasme peserta tinggi.
\end{abstract}

Kata Kunci: Pengarsipan Elektronik; IWSM; Wordpress; Blended Learning

\section{Abstract:}

The new curriculum which revises the SMK 2018, revised curriculum focuses on the used information and telecommunications technology. These curriculum have several renewals such as the emergence of the name office automation and governance and also the emergence of subjects with availability of digital and technology. One of the subjects highlighted was electronic archiving to answer these challenges. The purpose of this service were to improve the competence of teachers and staff of SMKN Cisarua in the field of electronic filing systems with the IWSM program and the introduction of the wordpress application. This service method hybird. Delta, the results of the evaluation of the average post test score compared to pree test, increased by $18 \%$, this shows a positive result. With the attendance rate of participants for 5 days of training of $82,4 \%$. This indicates that the high enthusiasm of the participants.

Keywords: Electronic Filing Systems; IWSM; Wordpress, Blended Learning 


\section{PENDAHULUAN}

Pendidikan vokasi adalah pendidikan yang mempersiapkan peserta didiknya untuk siap bekerja di berbagai lapangan pekerjaan yang ada di masyarakat. Keberhasilan suatu lembaga pendidikan vokasi ditandai dengan diterimanya para lulusan untuk bekerja di indurstri (Ma'mun Sutisna \& Firmansyah, 2020) Hal ini mencerminkan bahwa kompetensi yang dimiliki para lulusan dari lembaga pendidikan vokasi tersebut telah sesuai dengan tuntutan lapangan pekerjaan. Kurikulum SMK tahun 2013 direvisi pada tahun 2018 (Ma'mun Sutisna, Halilah, et al., 2020) Revisi mencakup isi mata pelajaran dan juga perubahan nama kompetensi keahlian menjadi Otomatisasi dan Tata Kelola Perkantoran (OTKP) yang sebelumnya adalah Administrasi Perkantoran. Salah satu perubahan yang dianggap penting adalah perubahan pada mata pelajaran yang awalnya bersifat manual menjadi bersifat elektronik, contohnya pengarsipan Pengelolaan arsip yang awalnya dilakukan manual, kini sudah berubah menjadi pengelolaan secara elektronik atau digital.

Kurikulum yang berkembang imbas penemuan dan penerapan teknologi insformasi dan komunikasi harus diikuti dengan peningkatan kemampuan guru baik substantif keilmuan maupun metodologi pengajaran (Ma'mun Sutisna, Halilah, et al., 2020). Padahal, dari pengalaman survey ke SMKN 1 Cipatat, banyak guru yang masih butuh ide segar untuk dapat mengembangkan bahan dan metode pembelajaran perihal mata pelajaran yang berbau teknologi. Setelah sukses menyelenggarakan PKM pada SMKN 1 Cipatat tahun 2020 lalu, muncul permintaan dari guru-guru SMKN 1 Cisarua untuk menyelenggarakan PKM dengan tema yang serupa di SMKN 1 Cisarua. Merujuk antusias pihak SMKN untuk berkolaborasi dengan Pendidikan Tinggi Vokasi, maka kegiatan PKM ini akan sangat membantu. Bukan hanya meningkatknya kemampuan guru untuk membekali siswa menghadapi dunia kerja, namun juga sejalan dengan cita-cita Dirjen Vokasi untuk dapat menciptakan sinergi antara SMK dan Politeknik.

Kompetensi e-filing yang termasuk dalam mata pelajaran Kearsipan tergolong relatif masih baru (Ma'mun Sutisna, Suhaeni, et al., 2020) sehingga masih memerlukan pelatihan khusus bagi guru-guru yang mengampu mata pelajaran tersebut, baik dalam hal kompetensi efilingnya maupun metode untuk mengajarkan e-filing tersebut agar siswa mencapai kompetensi yang diharapkan. SMKN 1 Cisarua relatif masih muda berdiri tahun 2015 beralamat Jalan JL. Raya Kolonel Masturi Cisarua, RT 01 RW 01, Kelurahan Jambudipa, Kecamatan Cisarua, Kabupaten Bandung Barat, Jawa Barat, 40551. Dengan luas tanah $14072 \mathrm{M}^{2}$ memiliki program studi; 4 Program Studi sebagai berikut 1) Otomatisasi dan Tata Kelola Perkantoran (OTKP) 2)Teknik Kendaraan Ringan Otomotif (TKRO) 3) Perhotelan (PH) dan 4) Rekayasa Perangkat Lunak (RPL).

Pemetaan kendala atau pemasalahan di Mitra Binaan dilakukan observasi dan wawancara pada tangal 25 Mei 2021 bertemu langsung dengan Kepala Sekolah SMKN Cisarua Ule Sulaeman, S.P., M.P. Wakasek dewan guru dan staf Tata Usaha. Mendapatkan temuan bahwa masih banyaknya guru-guru SMK pengampu mata pelajaran kearsipan khususnya e-filing yang belum siap secara maksimal karena keterbatasan kompetensi yang dimiliki adalah masalah umum yang dihadapi SMK Negeri 1 Cisarua. Hal ini dikarenakan masih belum memiliki kesempatan untuk mengikuti pelatihan atau sertifikasi kompetensi di bidang tersebut. Masalah dana yang dibutuhkan untuk mengikuti pelatihan dan sertifikasi kompetensi juga masih terbatas. Dari penelitian yang dilakukan (Joseph et al., 2012) didapatkan temuan manajemen kearsipan dampaknya lebih luas untuk praktik professional oleh karena itu staf Tata Usahapun mengikuti kegiatan pelatihan ini. 
Pengayaan pengabdian masyarakat ini penggunaan aplikasi IWSM, tim PKM juga akan memberikan overview perihal penggunaan wordpress. Wordpress merupakan salah satu content management system yang paling banyak digunakan dalam membuat dan mengembangkan website. Hal tersebut dikarenakan karakteristik dari wordpress yang sangat terbuka bagi pengembang untuk melakukan berbagai (O'Neill, 2017). Pengembang bebas untuk menentukan jenis hosting dan juga domain tanpa terikat. Selain itu, tersedia banyak forum yang dapat digunakan untuk berbagi ilmu dan juga pengalaman.

\section{METODE}

Pelaksanaan kegiatan pengabdian pada masyarakat dengan metode hybrid baik daring ataupun luring, ditempuh melalui tahapan-tahapanya mengadopsi dari kegiatan (Rachmawati, Rr: Firmansyah, 2021) sebagai berikut :

1. Melakukan survey dan wawancara lapangan dengan mitra SMKN I Cisarua kemudian merancang kegiatan pelatihan e-filing dan Metodologi Pengajaran vokasi serta pengenalan wordpress dilaksanakan secara luring pada tanggal 25 Mei 2021;

2. Memetakan permasalahan Mitra tentang Kearsipan elektronik, Kekurangan kompetensi kearsipan elektronik untuk peningkatannya terhambat anggaran untuk meningkatakan kompetensi guru dan staf tata usaha SMKN I Cisarua,

3. Merancang bentuk pengabdian kepada masyarakt : Pada tahap ini dikarekan kondisi pada saat itu adanya PPKM jadi sesuai kesepakan antara mitra dan Polban dilakukan secara hybrid.

4. Melakukan Tes Awal untuk mengetahui Kemampuan guru SMKN Cisarua tentang pembeajaran e-filing awal pelatihan tanggal 26 Juli 2021;

5. Melakukan pelatihan total selama 42 Jam, kurang-lebih 5 hari tentang, tanggal 26 juli sampai dengan 3 Agustus 2021 Secara daring menggunakan media Zoom Meeting ;

a) Merancang sistem kearsipan elektronik.

b) Pengoperasian program E-Filing.

c) Metode mengajarkan E-Filing. dengan metodologi pembeljaran vokasi

6. Melakukan tes akhir dengan mengevaluasi terhadap:

a) Proyek E-Filing. yang telah dibuat oleh peserta pelatihan dan

b) Performance peserta pelatihan dalam mengajarkan salah satu topik yang ada pada mata pelajaran Kerasipan khsususnya E-Filing.

c) Presentasi Rancangan Proyek EFS di satu perusahaan/instansi.

7. Melakukan monitoring dan evaluasi implementasi hasil pelatihan pada pembelajaran Mata Pelajaran e-filing di SMK Mitra dilakakuan tanggal 06 September 2021. Untuk menjadi umpan balik dikegiatan PKM selanjutnya. Lebih jelasnya digambarkan pada kerangka pemecahaan masalah sebagai berikut : 


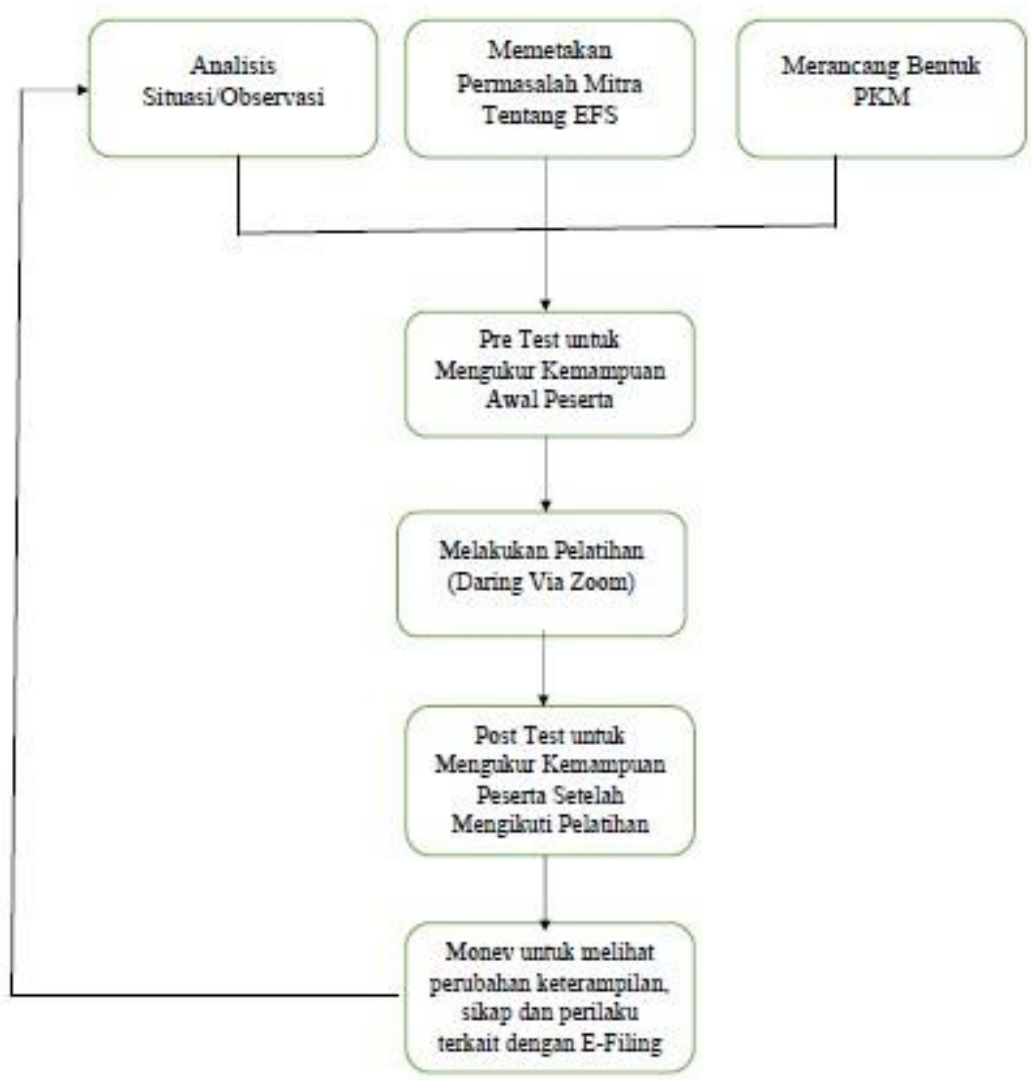

Gambar 1

Kerangka Pemecahaan Masalah Knowledge Sharing Penggunaan Aplikasi Pengarsipan Elektronik dengan IWSM dan Aplikasi Wordpress

\section{HASIL DAN PEMBAHASAN}

Pada tahap awal sampai ketiga dilakukan secara paralel berikut tahap pertama adalah melakukan survey, dilakukan pada tangal 25 Mei 2021 ; bertemu dengan pihak manajemen, dewan guru dan staf tata usaha untuk peningkatan kompetensi kearsipan elktronik memiliki keterbatasan material. Pada tahap kedua melakukan analisis penentuan permasalahan mitra tentang mitra ; Kompetensi pengarsipan elektronik merupakan mata pelajaran Kearsipan tergolong relatif masih baru (Ma'mun Sutisna, Suhaeni, et al., 2020) sehingga diperlukan pelatihan kearsipan elektronik bagi guru-guru yang mengampu mata pelajaran tersebut, baik dalam hal kompetensi kearsipan elektronik maupun metode untuk mengajarkan kearsipan elektronik tersebut agar siswa mencapai kompetensi yang diharapkan. Selain itu kompetensi ini juga diperlukan staf tata usaha oleh karena itu dapat diikutkan dalam pelatihan ini. Kekurangan kompetensi ini salah satu faktornya tidak ada anggaran khusus untuk pelatihan kearsipan elektronik. Pada tahap ketiga merancang bentuk PKM ; dengan melihat kondisi dan situasi pada saat pelatihan setelah berdiskusi pihak Mitra SMK yaitu PPKM, memutuskan kegiatan pelatihan daring, tetapi evaluasi dan monitoring bersifat luring.

Pada tahap keempat untuk mengukur kemampuan awal peserta dilakukan pre test untuk mengetahui kemapuan awal peserta, soal yang ada di pre test terdiri dari sepuluh soal 
berisikan tentang pengetahuan tentang kearsipan elektronik, penggunaan software image ware scan manager dan pengetahuan penggunaan CMS wordpress rata-rata mendapatkan nilai 55,71 . Pre test dilakukan dengan pertanyaan online menggunakan googleform.

Pada tahapan kekelima kegiatan PKM ini sudah terlaksana dengan baik walaupun ada hambatan seperti perpanjangan PPKM sehingga kegiatan inti pelatihan daring, sedangkan kegiatan luring pada saat observasi dan monitoring. Selanjutnya hasil secara rinci pelatihan pengarsiapan menggunakan aplikasi IWSM dan wordprees sebagai berikut:

Jumlah dan Keberhasilan Partisipan Pelatihan Pengariapan Elektonik dengan aplikasi IWSM dan Wordprees, pada tabel 1

\section{Tabel 1}

Jumlah dan Jenis kelamin Partisipan

\begin{tabular}{|clcc|} 
No & $\begin{array}{l}\text { Jenis } \\
\text { Kelamin }\end{array}$ & Jumlah & $\begin{array}{c}\text { Persentase } \\
\mathbf{( \% )}\end{array}$ \\
\hline 1 & Perempuan & 20 & 67 \\
\hline 2 & Laki-Laki & 10 & 33 \\
\hline & TOTAL & 30 & 100 \\
\hline
\end{tabular}

Pada tabel 1 manunjukkan jumlah Partisipan berjumlah 30 orang terdiri dari $67 \%$ Partisipan perempuan dan $33 \%$ Partisipan laki-laki. Peserta pelatihan ini terdiri dari guru dan staf tata usaha SMKN Cisarua Berikutnya tabel 2 menjelaskan tentang porsentasi kehadiran, sebagai berikut ;

Tabel 2

Kehadiran Partisipan

\begin{tabular}{cccc} 
No & Tanggal & Jumlah & $\begin{array}{c}\text { Persentase } \\
\text { (\%) }\end{array}$ \\
\hline 1 & 26 Juli 2021 & 22 & $73 \%$ \\
2 & 27 Juli 2021 & 25 & $83 \%$ \\
3 & 01 Agustus 2021 & 24 & $80 \%$ \\
4 & 02 Agustus 2021 & 26 & $86 \%$ \\
5 & 03 Agustus 2021 & 27 & $90 \%$ \\
& Rata-rata & & $82,4 \%$
\end{tabular}

Pada tabel 1 dapat dilihat persentase kehadiran masing-masing peserta perhari pada hari terakhir merupakan kehadiran tertinggi peserta sebesar $90 \%$ atau 27 peserta sedangkan yang terendah saat pembukaan sebesar $73 \%$ atau hanya 22 peserta, data ini didapat dari persensi pada setiap hari kegiatan pelatihan. Apabila kita rata-ratakan selama 5 hari pelatihan didapat peresntase sebesar $82,4 \%$. Ini menandakan tingkat antusisme peserta dengan pelatihan ini tinggi, peserentasi kehadiran tidak bisa $100 \%$ dikarenakan sebagaian peserta harus tetap 
menjalan tugas dari sekolah seperti mengantarkan siswa PKL (Praktek Kerja Lapangan) dan kegiatan penerimaan siswa baru. Selama lima pelatihan ini full daring menggunakan media zoom meeting premium dan website yang khusus dibuat untuk pelatihan ini dengan alamat http://polbandigitalmovement.com/ pelatihan dimulai dari jam 08.00 sampai dengan jam 15.00. Dalam prakteknya pelatihan interaksi narasumber dengan peserta sangat hidup mulai dari teori tentang pengarsipan elektronik sampai dengan mempratekkan langkah-langkah pengarsipan elektronik menggunakan aplikasi IWSM dan wordpress. Pada hari kempat pelatihan peserta memperaktekan hasil kerja kelompoknya dengan mempersentasikan hasil project pengarsiapan secara elektronik di lingkungan SMKN Cisarua. Dan pada hari terakhir bagaimana metodelogi pngajaran pengarsipan elektronik pada SMK atau vokasi, berikut Digambar saat pelatihan secara daring, pada gambar satu sebagai berikut:

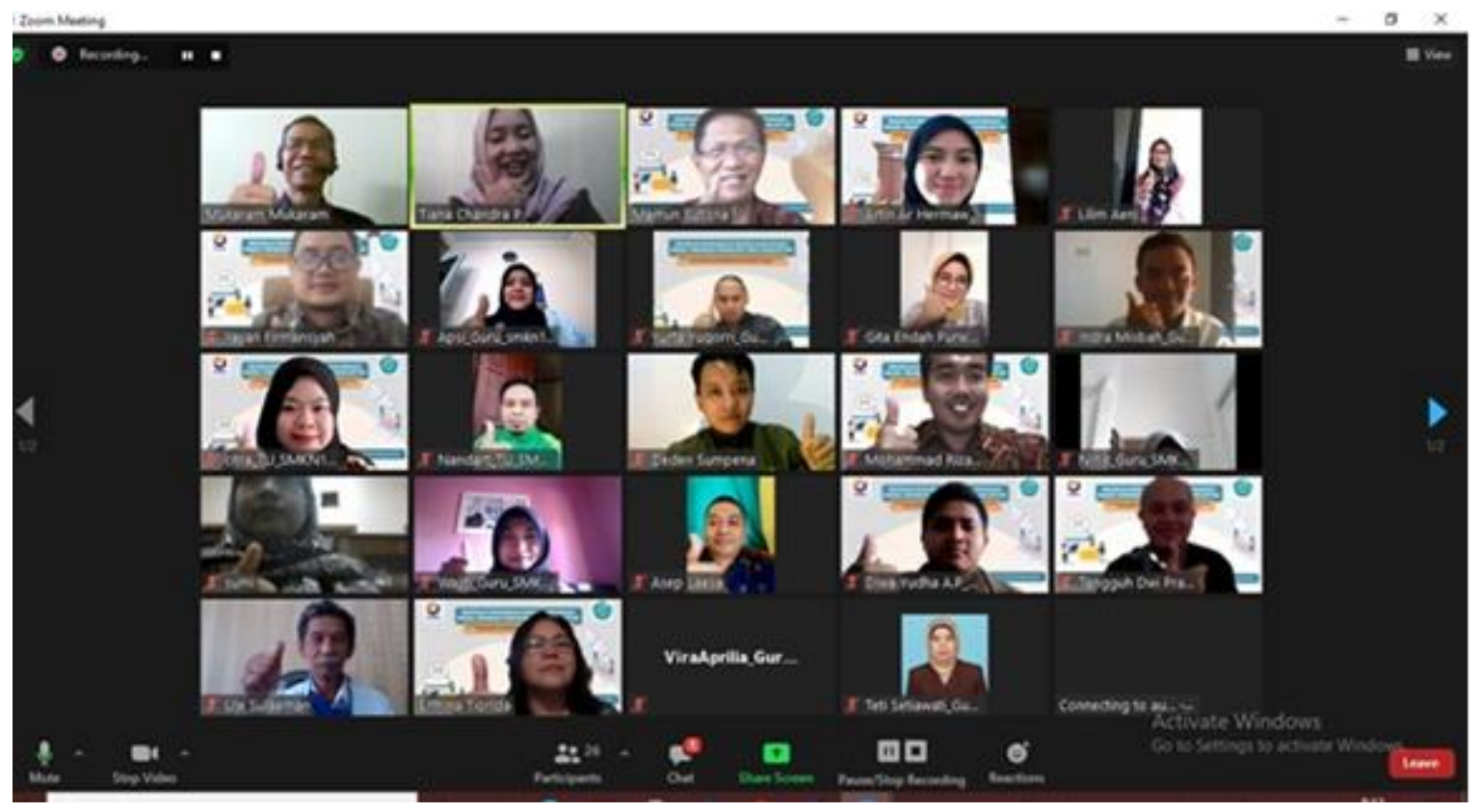

\section{Gambar 2}

\section{Suasana Pelatihan Secara Daring}

Pada gambar satu, memperlihatkan suasana pelatihan secara daring menggunakan Zoom Meeting, foto ini diambil pada akhir sesi setiap harinya, walaupun seharian penuh terlihat peserta dan narasumber masih tetap bersemangat, selanjutnya kita melihat hasil dari pelatihan dengan melihat delta atapi membandingkan hasil pre test dengan post test sebagai berikut:

\begin{tabular}{|rlr|}
\hline \multicolumn{4}{c}{ No } & \multicolumn{2}{c}{ Nilai Pre Test dan 3} \\
Nilai & $\begin{array}{c}\text { Post Test } \\
\text { Rata- } \\
\text { Rata }\end{array}$ \\
\hline 1 & Pre Test & 55,71 \\
2 & Post Test & 73,33 \\
& $\Delta$ (\% Perubahan) & $18 \%$ \\
\hline
\end{tabular}


Pada tahap keenam dilakukan post tes pada tabel 3 kita membandingkan hasil pre test dengan post test, caranya dengan memberikan soal yang sama dan diacak menggunkan googleform sebanyak 10 butir pertanyaan pilihan ganda, kenapa soal tersebut diacak dan soal berupa pilihan ganda untuk mengurangi faktor subjetifitas penilai. Hasil rata-rata nilai pretest peserta nilainya 55,71, sedangkan setelah ada pelatihan kita berikatan soal post test dan hasilnya rata-rata nilainya $73,33 \%$. Apabila kita bandingkan (Rata-rata nilai post test)-(Ratarata nilai pre test) dikalikan $100 \%$, mendapatkan delta perubahan sebesar $18 \%$, soal pre test dan post test membahasa tentang materi Image Ware Scan Manager dan CMS Wordpress; pengetahuan perangkat software kearsipan elektronik, keuntungan kearsipan elektronik, pengembangan CMS wordprees dilaptop sendiri tanpa menyewa hosting, teknis penggunaan Iwage Ware Scan Manager dan pengetahuan wordpress. Hasilnya mendapatkan delta perubahan sebesar $18 \%$, soal pre test dan post test membahasa tentang materi Image Ware Scan Manager dan CMS Wordpress ini mengindikasikan kegiatan PKM ini ada manfaatnya, selain itu untuk menguju keterampilan peserta melakukan pengerjaan project dan diujikan ratarata kelompok yang mempersentasikan hasil kerjanya mendaptkan nilai 85 , berikut gambar monitoring dan evaluasi yang dilakukan secara luring sebagai berikut :

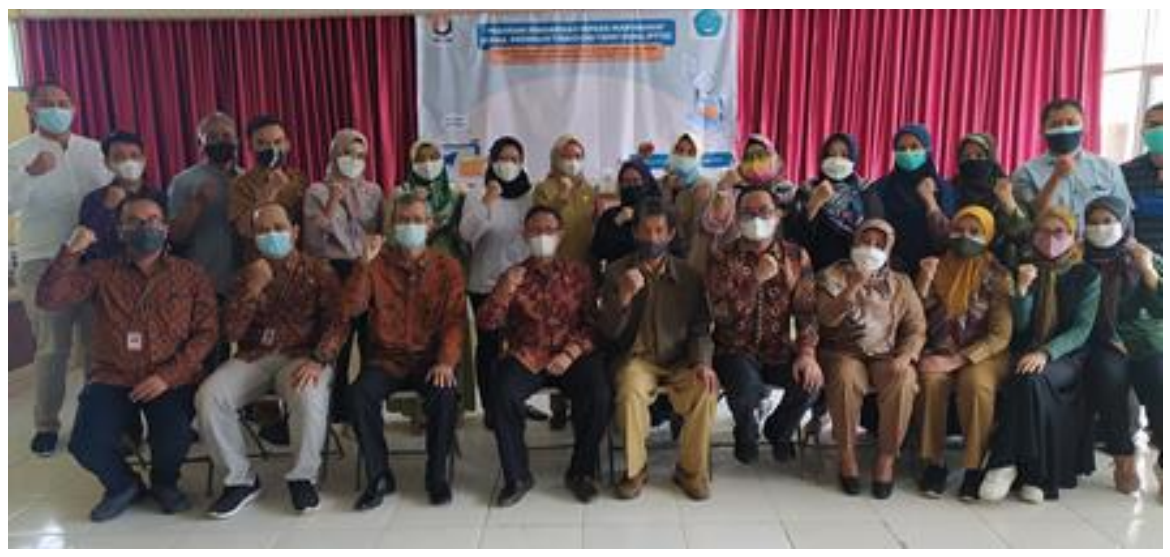

Gambar 3

Suasana Monitoring dan Evaluasi

Pada tahap ketujuh, monitoring dan evaluasi (monev) dilakukan pada tanggal 06 september 2021, dilakukan secara luring dengan menerapkan protokel Kesehatan yang ketat, kegiatan monev ini bertempat di SMKN I Cisarua, dengan hasil implementasi dan hasil project kearsipan elektronik, beberapa peserta melakukan demontrasi hasil project-nya seperti dibeberapa bagian sekolah seperti perpustakaan dan bagian kerjasama industry, selain itu mendaptakan masukan secara langsung kegiatan PKM, baik data dari googleform tentang evaluasi PKM dan diskusi langsung, peserta menyatakan puas dengan kegiatan PKM ini ada beberapa catatan 1. Metode PKM mohon dipertimbankan agar luring semua karena PKM ini Sebagian besar bersipat workshop atau peraktek 2. Melanjutkan kegiatan PKM ini dengan memperdalam yang sudah ada terutama pengarsipan yang bersifat website seperti wordpress. 


\section{SIMPULAN}

Pelaksanaan PKM ini memiliki keterbatasan secara umum, dengan mencermati kondisi saat ini dalam pandemic covid-19 dan pemberlakukaan PPKM kegiatan initi PKM dilakukan secara daring melalui zoom meeting, sedangkat observasi dan monev dapat dilakukan secara luring, meskipun demikian tujuan PKM ini dalam upaya peningkatan kompetensi guru-guru dan staf SMKN Cisarua dalam bidang sistem kerasipan elektronik dengan program IWSM dan pengenalan aplikasi wordpress dapat dikatakan berhasil. Dapat kita lihat dari delta perubahan nilai post tes dan pre test sebesar $18 \%$, selain itu juga dapat dilihat dari hasil project dan peresentasi permasing-masing kelompok rata-rata nilainya 85 , ini menandakan kegiatan PKM ini memiliki dapat manfaat baik secara teori dan praktis.

\section{UCAPAN TERIMA KASIH}

Terimaksih kepada semua pihak yang terlibat di PKM ini, Manajemen Polban ; kepala PPPM beserta jajarannya yang memberikan fasilitan dalam kegiatan PKM ini, Ketua jurusan Administrasi Niaga berserta jajarannya, Kepala Sekolah SMKN 1 Cisarua beserata jajarannya, serta mahasiswa dan semua yang terlibat dalam kegiatan PKM.

\section{REFERENSI}

Joseph, P., Debowski, S., \& Goldschmidt, P. (2012). Paradigm shifts in recordkeeping responsibilities: Implications for ISO 15489's implementation. Records Management Journal, 22(1), 57-75. https://doi.org/10.1108/09565691211222108

O'Neill, J. L. (2017). Deploying a WordPress-based learning object repository to scale up instruction and effect a culture of sharing. Reference Services Review, 45(1), 131-140. https://doi.org/10.1108/RSR-10-2016-0059

Rachmawati, Rr: Firmansyah, Y. (2021). Pengaruh Motivasi Dan Mental Berwirausaha. Jurnal Dharma Bhakti Ekuitas, 05(02), 511-515. https://doi.org/https://doi.org/10.52250/p3m.v5i2.105

Sutisna, Ma'mun, \& Firmansyah, ; Sholihati Amalia; Sri Surjanii; Yayan (Eds.). (2020). E-FILING SYSTEM SMK (1st $\quad$ ed.). Qiara https://www.google.co.id/books/edition/BUKU_AJAR_PRAKTIKUM_E_FILING_SYSTEM_S $\mathrm{MK} / 2 \mathrm{coLEAAAQBAJ} ? \mathrm{hl}=\mathrm{id} \& \mathrm{gbpv}=1 \& \mathrm{dq}=\mathrm{Buku}+\mathrm{ajar}+$ pratikum+E-

Filing+System+SMK\&printsec $=$ frontcover

Sutisna, Ma'mun, Halilah, I., Amalia, S., Tjahjawati, S. S., Firmansyah, Y., \& Setiawan, I. (2020). Pengembangan Buku Ajar Dan Blended Training E-Filing System Dengan Program Iwsm Di Smkn I Cipatat. Dharma Bhakti Ekuitas, 5(1), 489-499. https://doi.org/10.52250/p3m.v5i1.321

Sutisna, Ma'mun, Suhaeni, T., Setiawardani, M., Mukaram, M., Raharso, S., Tiorida, E., \& Harmon, H. (2020). Pengembangan Pembelajaran Kearsipan Melalui Pelatihan Electronic Filing System (EFS) dengan Program IWSM di Sekolah Menengah Kejuruan (SMK). JURNAL PENGABDIAN KEPADA MASYARAKAT (AbdiMas), 2(1), 17-33. https://doi.org/10.30871/abdimas.v2i1.1875

Website http://polbandigitalmovement.com/diakses tanggal 26 Juli sampai 03 Agustus 2021 